\title{
Myxomycete colonization on translocated and non-translocated dead leaves from temperate and tropical forests
}

\author{
Rojas $\mathrm{C}^{1,2^{*}}$, Stephenson $\mathrm{SL}^{3}$ and Rojas $\mathrm{PA}^{2}$
}

\author{
${ }^{1}$ Finca Experimental Interdisciplinaria de Modelos Agroecológicos, University of Costa Rica, Turrialba, 30502-Costa \\ Rica \\ ${ }^{2}$ Engineering Research Institute, University of Costa Rica, San Pedro de Montes de Oca, 11501-Costa Rica \\ ${ }^{3}$ Department of Biological Sciences, University of Arkansas, Fayetteville, AR 72701, USA
}

Rojas C, Stephenson SL, Rojas PA 2020 - Myxomycete colonization on translocated and nontranslocated dead leaves from temperate and tropical forests. Studies in Fungi 5(1), 462-470, Doi 10.5943/sif/5/1/27

\begin{abstract}
Samples of dead leaves on the forest floor were collected from a locality in central Costa Rica and another locality in northwest Arkansas in the United States and then were placed in fine-mesh nylon bags, autoclaved and left out in the field for four months. Half of the bags prepared with sterile material from each country were placed out in the country where they were collected, and the other half were placed in the other country. A characterization of forest structure and ground leaf chemistry was carried out for both localities and both leaf types. When recollected, all samples were processed for myxomycetes with the use of the moist chamber culture technique. The cultures yielded a total of 156 records of myxomycetes representing 16 species, but only 13 records and six species were isolated from the samples left out in Costa Rica. One hundred percent of cultures placed out in Arkansas produced myxomycetes, whereas only 68\% of those placed out in Costa Rica were positive for these organisms. Differences in species richness and number of records were observed across forests where the samples were placed out, and no differences were observed based on the origin of the leaves. Results suggested that myxomycete colonization in the studied areas is primarily affected by the dynamics of the forest type and secondarily by substrate attributes. Some myxomycete species recorded on leaves with poorer chemical values are also consistent with field data. In the present study, the more open character of the temperate forest in Arkansas without a film of water layer covering the leaves on the ground seemed to have played a role in the establishment of myxomycete propagules in the sterile material during the time of the investigation.
\end{abstract}

Key words - Arkansas - Costa Rica - myxogastrids - Pea Ridge - slime molds - Turrialba

\section{Introduction}

Myxomycetes (plasmodial slime molds or myxogastrids) are a group of fungus-like organisms associated with dead plant material in virtually every type of terrestrial ecosystem investigated to date, with approximately 1000 species known worldwide (Lado 2005-2020). The myxomycete life cycle encompasses two very different trophic (feeding) stages, one consisting of uninucleate amoebae, with or without flagella (the term "amoeboflagellate" is used to refer to both types), and the other consisting of a distinctive multinucleate structure, the plasmodium (Martin et al. 1983). Under favourable conditions, the plasmodium gives rise to one or more fruiting bodies 
containing spores, which are mostly dispersed by wind but incidental dispersal by animals undoubtedly represents a factor of some importance.

Ground litter (consisting mostly of dead leaves) on the forest floor is one of the primary substrates for myxomycetes (Martin \& Alexopoulos 1969, Stephenson \& Stempen 1994). Results from studies (e.g. Harkönen 1981, Stephenson 1989, Stephenson et al. 1999) of this substrate have indicated that ground litter in both temperate and tropical forests supports a diverse assemblage of these organisms. Presumably, when a leaf dies and falls to the forest floor, it quickly acquires airborne spores of myxomycetes. It is possible that some spores are acquired before the leaf falls to the forest floor, but this is difficult to determine. In any case, some of the spores germinate and ultimately have the potential of facilitating the completion of the myxomycete life cycle by allowing these organisms to produce fruiting bodies.

Previous studies have shown differences in the species of myxomycetes associated with different types of ground litter from a single locality (see Rollins \& Stephenson 2012). It is known that qualitative differences in the dead leaves such as relative positioning within the ground litter layer, the stage of decomposition and the species of plant from which they were derived play a role in determining the particular species of myxomycetes present. However, quantitative approaches focusing on the dead leaves as the primary agents of myxomycete growth and development are not common, and as a result less information has been accumulated. The leaves produced by plants in both temperate and tropical forests can be chemically different and also are influenced by distinctly different structural characteristics of the ecosystem in which they occur, including wet-dry cycles mediated by canopy openness (see Keller \& Phillips (2019) for a discussion of biotic interactions). This can affect effective colonization of leaves by myxomycetes by favouring or not favouring their establishment.

One effective strategy to address the latter as a factor for myxomycetes is by designing a simple matrix experiment where both forest and litter types are studied at all levels. However, for such an experiment to take place, a translocation of material is necessary to evaluate the cross-level combination (i.e., leaf from ecosystem $a$ placed in ecosystem $b$ and vice versa). For the topic of myxomycete colonization, this approach offers the possibility of evaluating the effect of quantifiable indicators associated with the dead leaves and/or with the forest ecosystems (similar to Fukasawa et al. (2015) for coarse woody debris). This would facilitate addressing the issue of whether some species of myxomycete have colonization strategies associated with specific forest ecosystems or with specific substrate conditions.

The project described herein was designed to partially address those questions by comparing occurrence-based results associated with substrates with a common origin in different forest ecosystems. This type of experiment has the capacity to provide valuable feedback for more complex studies of myxomycete colonization and the role of the environment in shaping this process. In terms of biocomplexity, the quantification of the modulation assisted by the elements of the ecosystem (i.e., the types of leaves) is important to generate more realistic models of substrate interactions, which in relation to myxomycetes, could help us increase our understanding of their ecological role.

\section{Materials \& Methods}

Samples of intact dead leaves were collected from the forest floor in (1) an oak-hickory forest in the Pea Ridge National Military Park $\left(36^{\circ} 27^{\prime} 29^{\prime \prime} \mathrm{N}, 9^{\circ} 01^{\prime} 17^{\prime \prime} \mathrm{W}\right.$; elevation $\left.485 \mathrm{~m}\right)$ in northwest Arkansas in the United States of America and (2) a tropical premontane wet forest in the Finca Experimental Interdisciplinaria de Modelos Agroecológicos or FEIMA (09 $51^{\prime} 47^{\prime \prime} \mathrm{N}, 83^{\circ} 38^{\prime} 07^{\prime \prime} \mathrm{W}$; elevation $625 \mathrm{~m}$ ) near the town of Turrialba in central Costa Rica. The material from Pea Ridge, which consisted of a mixture of leaves from Quercus alba, Q. velutina, Carya tomentosa and Ulmus alata (collected 10 August 2018), was transported to the Eumycetozoan Laboratory at the University of Arkansas. The material from FEIMA, which consisted of a mixture of leaves from Erythrina poeppigiana and Cecropia sp. (Collected on 20 August 2018) was taken to the Engineering Research Institute at the University of Costa Rica. Half of the material from each study 
area was kept in the original laboratory and the other half was sent to the complementary laboratory, after which all of the samples from each of the two study areas were cut into small pieces (ca 2 to $5 \mathrm{~cm}$ ), enclosed in $15 \mathrm{x} 15 \mathrm{~cm}$ high-density polyethylene (HDPE) mesh bags with $0.27 \mathrm{~mm}$ pore size, and autoclaved.

These sterile bags with dead leaves (from both collecting localities) were taken back to the two study areas from which the original material was collected. They were placed out in the field at Pea Ridge on 3 September 2018 and at FEIMA on 1 October 2018. The bags were placed on the ground along two parallel transects (Fig. 1), with 25 bags containing the samples from Arkansas in one transect and 25 bags containing the samples from Costa Rica in the second transect. As such, one transect consisted of bags with non-translocated sterile leaves in their forest of origin and the other transect consisted of bags with translocated sterile leaves in a different forest. All bags were recollected after approximately four months in the field, on 6 January 2019 at Pea Ridge and on 6 February 2019 at FEIMA.

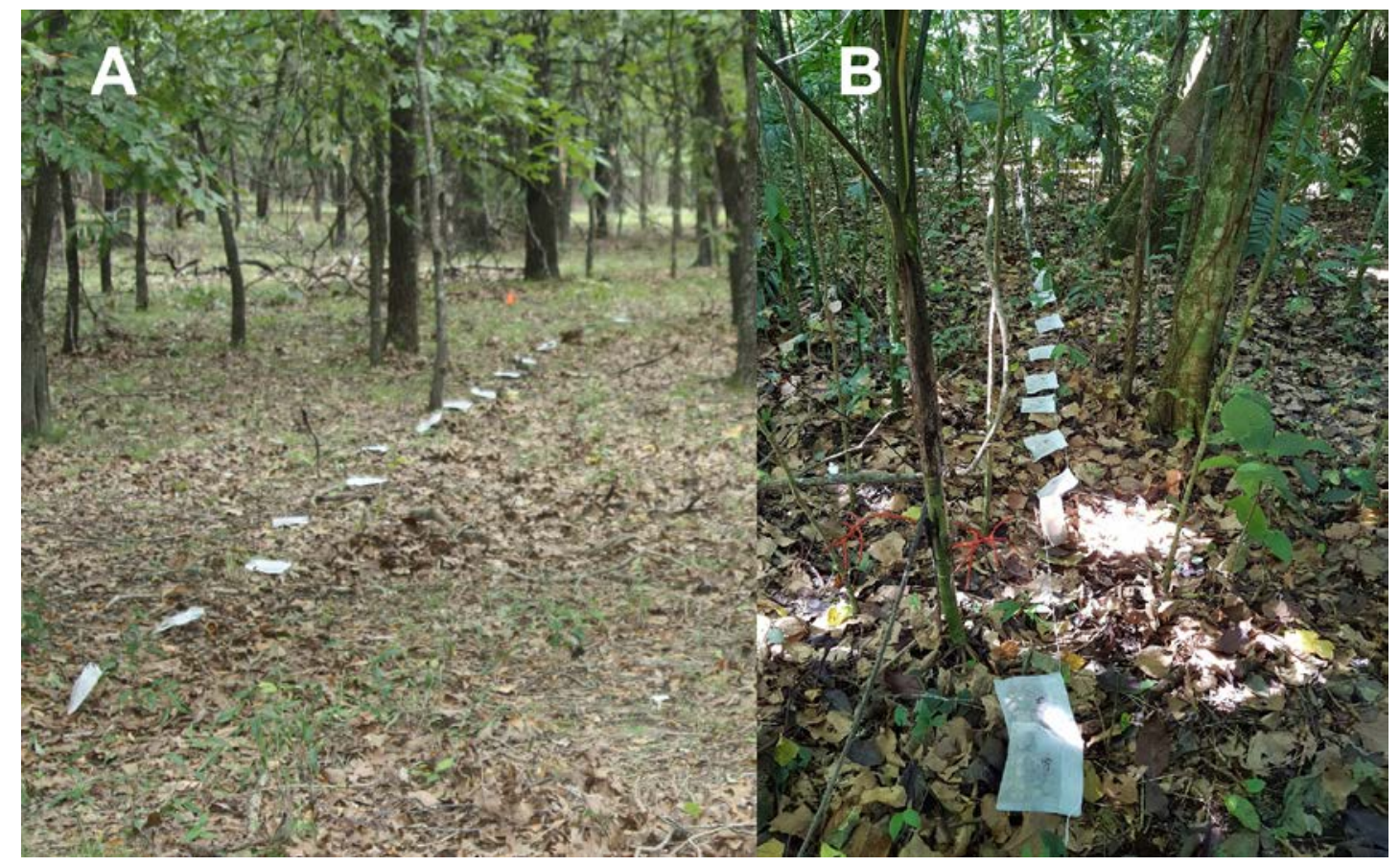

Fig. 1 - Transects of mesh bags containing the sterile dead leaves when placed out in the field at Pea Ridge (A) and FEIMA (B) during the fall of 2018. The bags were left in those conditions for a period of four months, during which, natural colonization of myxomycetes took place.

In both laboratories in Arkansas and Costa Rica, the dead leaves contained within the bags were used to prepare two series of moist chamber cultures. These were prepared in the manner described by Stephenson \& Stempen (1994) and consisted of plastic disposable Petri dishes (90 mm diameter) lined with filter paper. Three Petri dishes were prepared from each of the bags, for a total of 75 for each study area and a total of 150 for the entire project. Extra samples of originally autoclaved dead leaves were used as controls to make five more cultures from each forest type. The assumption of this experiment was that the sterile dead leaves within the bags were colonized by myxomycetes for four months, and that such information could partially be recorded with the moist chamber technique.

Enough sample material was placed in each dish to cover most of the bottom, and the material was moistened with distilled water. After a period of approximately 24 hours, the $\mathrm{pH}$ of each culture was determined with a portable $\mathrm{pH}$ meter and then excess water in the Petri dish was poured off. Moist chamber cultures were placed out of direct sunlight and maintained at room temperature. Water was added to these cultures when necessary to maintain moist conditions, and the cultures were checked at least twice each week for evidence (either plasmodia or fruiting 
bodies) of myxomycetes over a period of approximately three months. When fruiting bodies were observed, they were recorded, removed from the moist chamber culture, air-dried and placed in small pasteboard boxes for long-term storage. A specimen was defined as a record of the occurrence of one or more fruiting bodies of a particular species of myxomycete in a single culture. With this information, a table of records was created and two estimators of productivity - species richness and number of records - were calculated for each sample. These calculated values were used as response variables in posterior analyses.

In addition to the leaves collected for preparation of moist chamber cultures, five samples from each of the two study areas were ground into a coarse powder and then sent to Brookside Laboratory (New Bremen, Ohio) for chemical characterization of macro- and microelements. These variables were used to determine the chemical attributes of the leaves from each forest type, one of the factors considered in this investigation. In a similar manner, to characterize the forest structure in each study area, the other factor of investigation, field-based variables such as tree height, tree diameter, number of trees/200 $\mathrm{m}^{2}$, basal area, canopy openness and leaf area index were obtained or calculated in each study area. For canopy openness and leaf area index, hemispherical photography was used, and post-processing was carried out in the Gap Light Analyzer software. Trees were considered as woody plants with stem diameters greater than $10 \mathrm{~cm}$.

The statistical analyses were conducted to test the null hypotheses that the response variables were not different at either of the levels of the evaluated factors. For this, two 2-way ANOVAS were used after normalizing data, one for each response variable. In these tests, a cutoff value of 0.05 was used in the rejection of the null hypothesis. With the biodiversity level data (records of myxomycetes by species) for the four possible combinations (two forests and two leaf types), differences in the datasets were evaluated using t-tests on the Shannon Diversity Index. Also, a cluster analysis based on the Jaccard Index, as discussed by Chao \& Chun-Huo (2016), was implemented to see affinities in the datasets using taxonomic data. All tests were carried out in the software PAST, v4.01 (Hammer et al. 2001). The nomenclature used follows Lado (2005-2020).

\section{Results}

A total of 156 records of myxomycetes representing 16 species were tallied, with only 13 records and six species isolated from the samples left out in the tropical forest. Curiously, about $68 \%$ of the moist chambers with the same material showed myxomycete activity, mostly in the form of plasmodia that never fruited during the time of the experiment (Table 1). In contrast, 100\% of the samples left out in the temperate forest showed myxomycete activity but none showed only plasmodia. Controls did not show any evidence of myxomycetes.

Arcyria cinerea, Cribraria violacea and Perichaena chrysosperma were the only species recorded only on leaves placed out in both forest types. Hemitrichia minor was notably recorded on tropical leaves in FEIMA, and Physarum bivalve and Diderma effusum were recorded only on temperate leaves in Pea Ridge. Species in such genera as Didymium, Perichaena, Cribraria, and Lamproderma showed some preference for tropical leaves, whereas species of Arcyria, Diderma, and Physarum were mostly associated with temperate leaves.

Both species richness and the number of records of myxomycetes associated with the leaf samples were higher in Pea Ridge than in FEIMA (Fig. 2), and differences were not apparent within each of the two forest types. As such, differences in the two estimators were observed across localities where the colonization experiment took place $(F(1,96)=19.7, P<0.0001$ for species richness and $F(1,96)=58.7, P<0.0001$ for number of records) but no differences were observed between leaf types $(F(1,96)=2.2, P<0.14$ for species richness and $F(1,96)=2.7, P<0.09$ for number of records). The interaction effect of forest and leaf types was observed for species richness $(F(1,96)=7.2, P<0.008)$ and not observed for number of records $(F(1,96)=2.7, P<0.10)$. The same pattern was observed when taxonomic data were used in the cluster analysis (Fig. 3). The Shannon Diversity Index was different between the sets of tropical leaves (i.e. tropical leaves left out in the two different forest types, $t=3.65$, d.f. $=12, P=0.003$ ) but not different for any other combination. 
The general conditions of the two forests were different at the time of the experiment, with Pea Ridge showing more trees per unit area. However, these trees were shorter and had lower stem diameters (Table 2) than those in FEIMA. As expected, canopy openness was lower, and leaf area index was higher in FEIMA, indicating a more closed canopy and more layers of vegetation in the tropical forest. In terms of chemical quality of the leaves, most of the evaluated elements showed higher values in leaves produced by tropical trees (originally collected in FEIMA), with the exception of manganese, zinc, and aluminum, which were higher in leaves with a temperate origin. The $\mathrm{pH}$ values at the time the moist chamber cultures were prepared were higher for tropical leaves and lower for temperate leaves, particularly for those associated with Pea Ridge, where the extreme values were observed $(F(3,192)=449, P<0.0001)$.

Table 1 Number of records of myxomycetes obtained for both leaf types placed out in both experimental forests, arranged by species. The number of non-fruiting plasmodia recorded for each level is also provided.

\begin{tabular}{|c|c|c|c|c|}
\hline \multirow[b]{2}{*}{ Species } & \multicolumn{2}{|c|}{ Pea Ridge } & \multicolumn{2}{|l|}{ FEIMA } \\
\hline & $\begin{array}{l}\text { Tropical } \\
\text { leaves }\end{array}$ & $\begin{array}{l}\text { Temperate } \\
\text { leaves }\end{array}$ & $\begin{array}{l}\text { Tropical } \\
\text { leaves }\end{array}$ & $\begin{array}{l}\text { Temperate } \\
\text { leaves }\end{array}$ \\
\hline Arcyria cinerea & & 4 & 2 & 1 \\
\hline Cribraria violacea & 18 & & 2 & 1 \\
\hline Didymium clavus & 5 & 4 & & \\
\hline Didymium minus & 7 & & & \\
\hline Didymium squamulosum & 5 & 2 & & \\
\hline Diderma effusum & & 14 & & \\
\hline Diderma hemisphaericum & 6 & 2 & & \\
\hline Hemitrichia minor & & & 1 & \\
\hline Lamproderma scintillans & 16 & 3 & & \\
\hline Perichaena chrysosperma & 3 & & 4 & \\
\hline Perichaena pedata & 1 & 4 & & \\
\hline Perichaena vermicularis & 17 & 5 & & \\
\hline Physarum bivalve & & 16 & & \\
\hline Physarum cinereum & & & & 1 \\
\hline Physarum melleum & 7 & 4 & & \\
\hline Stemonitis fusca & & & & 1 \\
\hline Samples with plasmodia & 0 & 1 & 7 & 14 \\
\hline Number of species & 10 & 10 & 4 & 4 \\
\hline Number of records & 85 & 58 & 9 & 4 \\
\hline
\end{tabular}

\section{Discussion}

The experiment described herein clearly showed that myxomycete colonization occurs naturally on substrates associated with the forest floor. For both sets of leaves (translocated and non-translocated) within the study areas, the values associated with the results were similar and differences were observed only across localities where the samples were placed for colonization to occur. This clearly suggests that myxomycete colonization dynamics are primarily regulated by the ecological system (forest type in this case), as observed by Baldrian (2017) for soil microorganisms. The cluster analysis carried out with the results also showed the same pattern using taxonomic information.

In a similar experiment carried out in the same two study areas, but based on aerial substrates, an equivalent pattern was observed (i.e., differences in indicators between forest types as reported by Stephenson \& Rojas (2020)). However, in such a study the pattern of productivity in moist chamber cultures was exactly the opposite of the results presented herein, with substrates placed out in the tropical system yielding more myxomycetes. In this respect, the integrated results suggested that the spore load is higher above the ground and lower at ground-level in the studied tropical ecosystem in comparison with the temperate ecosystem. For instance, with a similar sampling 
effort, a total of 14 species were recorded on aerial substrates at FEIMA, whereas the present study recovered only six species out of a total of 16 observed for the complete experiment.
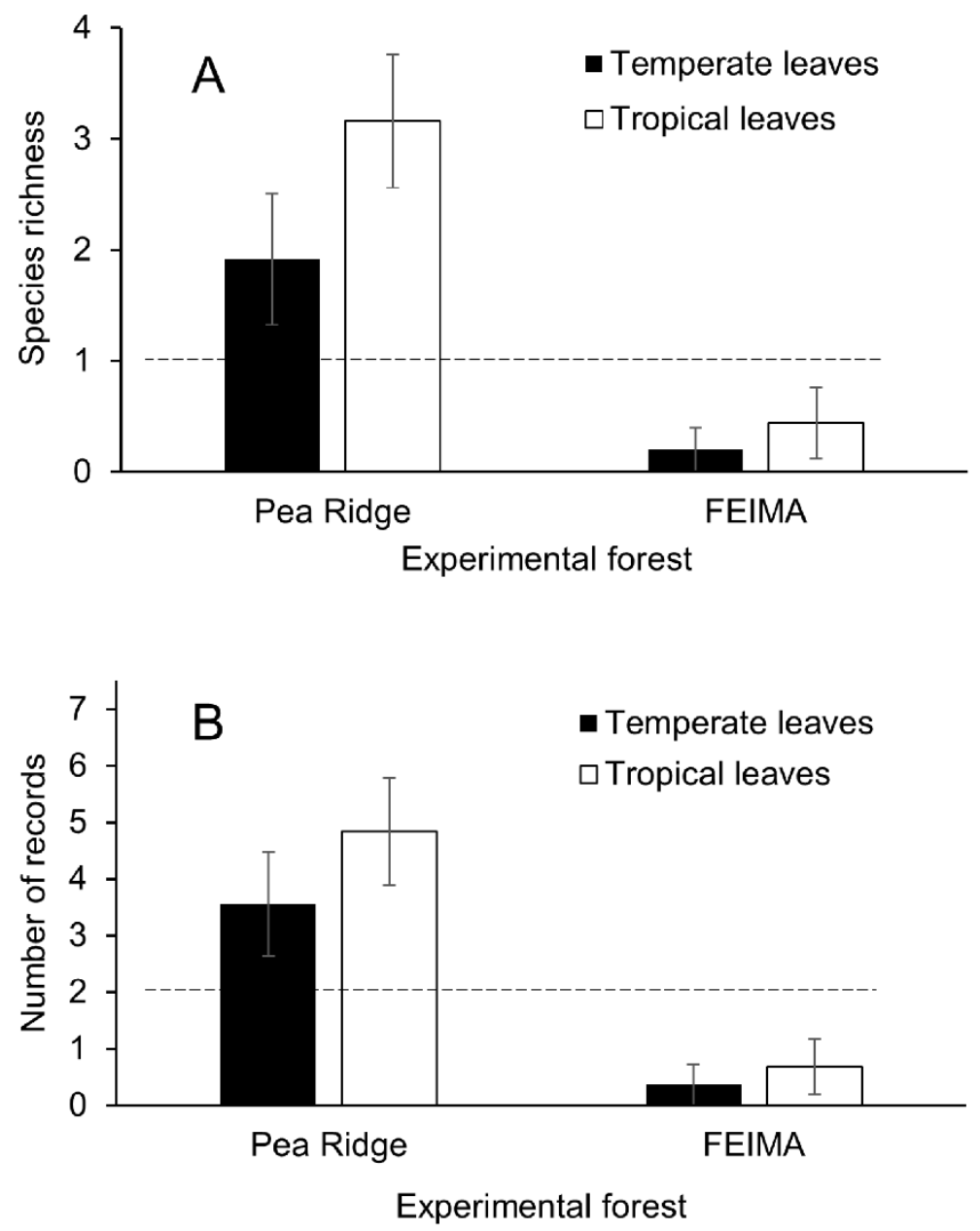

Fig. 2 - Average values per sample of the two response variables $(\mathrm{A}=$ species richness, $\mathrm{B}=$ number of records), arranged by locality where the colonization took place (experimental forest) and leaf type. Standard deviations on the bars and dotted lines on Y axes were added to show absence of overlap between localities.

One possible confounding factor, for ecological purposes, could be the combination of precipitation and water infiltration rates on the ground of the two study areas. During the time of the experiment, precipitation in both areas was similar (see data in Stephenson \& Rojas (2020)), but the general perception was that the forest at Pea Ridge was dryer than the forest at FEIMA, which can be related to slower infiltration in the tropical locality (see Mora-Chacón et al. 2019). If this is the case, the data recorded in the present study could also show that a constant film of water on substrates (ground litter in this case) has the potential of "washing away" the spores or propagules that can theoretically form fruiting bodies. This would indirectly reflect the different effect of the local seasonal patterns on the dynamics of myxomycetes. For instance, during most of the experiment, the forest at Pea Ridge was under the influence of the temperate autumn season, whereas the forest at FEIMA was influenced by the tropical rainy season.

In any case, the results suggested that the chemical characteristics of the dead leaves may determine secondarily the particular species that form fruiting bodies at a given locality. As observed, even some genera were associated with one of the leaf types studied in the present investigation. The difference in the Shannon Diversity Index for tropical leaves also supports this idea and the lack of differences for temperate leaves is likely related to the low number of records 
isolated in Costa Rica. Even though these characteristics may actually determine the presence of other microorganisms that myxomycetes feed upon, they indirectly represent a form of niche partitioning. Such splitting has been well documented in the genus Ceratiomyxa (Rojas et al. 2008) and would not be surprising to shape the occurrence of species in some common genera of myxomycetes on ground litter (i.e. Didymium).

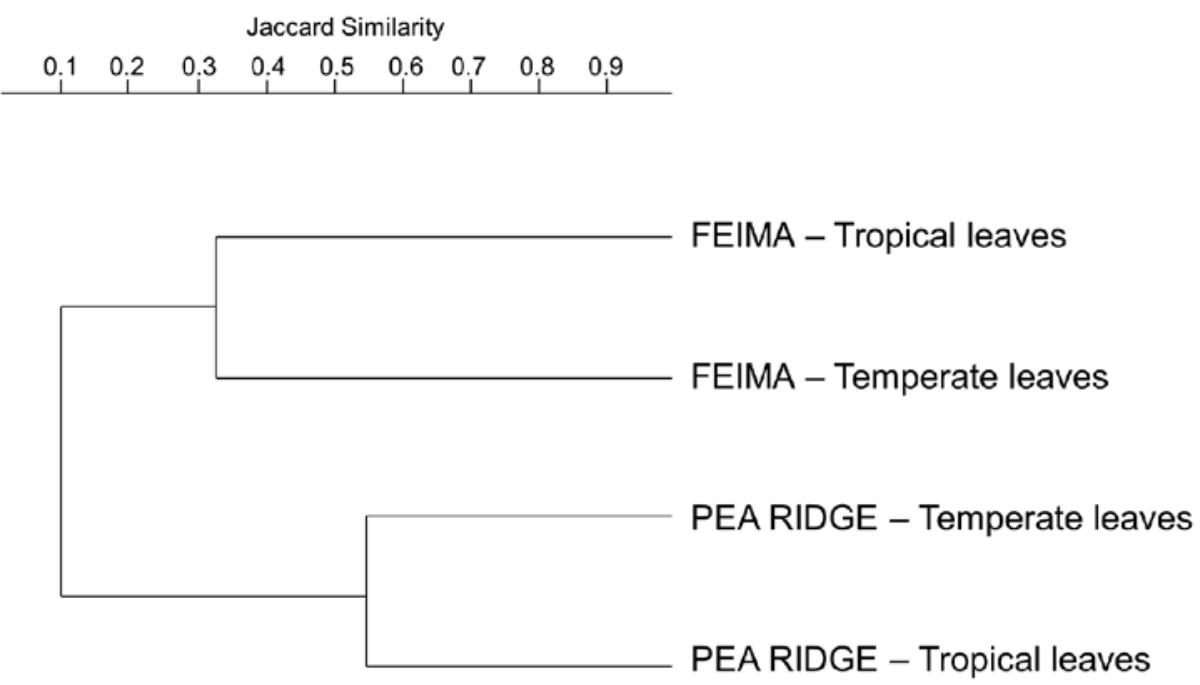

Fig. 3 - Cluster diagram based on the Jaccard Index of Similarity calculated with taxonomic data, showing the relative relationships of the four possible combinations of evaluated levels in the present study.

For instance, lower nutrients in the temperate leaves were associated with the occurrence of Physarum bivalve and Diderma effusum, and higher nutrients were associated with Cribraria violacea and Perichaena vermicularis. This is interesting because the first two are rare in lowland tropical forests but not uncommon in montane tropical forests where nutrients in litter are also similar to those in temperate forests (Vitousek 1984). Moreover, the latter two species are not particularly common in the eastern part of the United States (Stephenson et al. 2020). In general, tropical resources are richer in nutrients than those from temperate forests (see Nye 1960, Martinelli et al. 1999), but cycling dynamics (i.e. how quickly they decompose) are also much more rapid in the former. With translocated material, the first factor still plays a role but not the second one since all leaves within a particular locality are subjected to equivalent nutrient cycling forces. In this manner, for the present study, forest type (and its intrinsic ecological forces) was the primary driver of response variables, but differences in the chemistry of the dead leaves seemed to have influenced the occurrence of species. It would be interesting to further study whether this result is a natural process or simply an effect that takes place within the microcosm of the moist chambers.

In general, the more open forest in Pea Ridge (smaller basal area, higher canopy openness, and lower leaf area index (see Fig. 1)) allows a more fluid circulation of air. The latter facilitates the dispersal and colonization potential of myxomycetes and accelerates the natural drying processes that take place on the ground after rainfall. Even though myxomycetes use dead plant material as substrates to carry out their life cycle, it seems that as long as these materials are present, myxomycetes will occur (see results from dramatically dry environments such as the Namibian desert in Stephenson et al. (2019)). In this manner, it seems that finer differences in the quality of those substrates could promote the occurrence of some species over others but not necessarily determine the existence of the group. A similar, secondary effect would be facilitated by seasonal differences. 
The present study is important in the context of the rapid changes that forests are being subjected to worldwide. The generation of scientific data, particularly for microbial organisms, is essential to understand the finer dynamics that allow forests to exist. It is only in recent years that the scientific community has understood the importance of the "unseen majority" of the biota for the functioning of forest ecosystems and even human survival (see Cavicchioli et al. 2019). However, from another perspective, it is also necessary to understand how these forest ecosystems shape biological processes associated with those organisms. The results of this study add to the body of comparative information on the myxomycetes associated with temperate and tropical ecosystems and provide interesting ideas for future research.

Table 2 Average values for the chemical (leaf level) and ecological (forest level) related variables estimated in the present study by experimental forest. Higher values are shown in bold

\begin{tabular}{lll}
\hline Parameter evaluated & FEIMA & Pea Ridge \\
\hline Leaf related & & \\
Nitrogen (\%) & $\mathbf{2 . 2 1}$ & 0.98 \\
Phosphorous (\%) & $\mathbf{0 . 1 2}$ & 0.05 \\
Magnesium (\%) & $\mathbf{0 . 4 5}$ & 0.14 \\
Potassium (\%) & $\mathbf{0 . 2 3}$ & 0.09 \\
Calcium (\%) & $\mathbf{2 . 6 5}$ & 0.99 \\
Sulfur (\%) & $\mathbf{0 . 1 6}$ & 0.07 \\
Boron (ppm) & $\mathbf{3 1 . 6 4}$ & 14.00 \\
Iron (ppm) & $\mathbf{7 6 9 . 6}$ & 147.8 \\
Manganese (ppm) & 158 & $\mathbf{1 2 9 2}$ \\
Copper (ppm) & $\mathbf{9 . 3 0}$ & 8.12 \\
Zinc (ppm) & 27.44 & $\mathbf{3 1 . 5 4}$ \\
Aluminum (ppm) & 990.20 & $\mathbf{1 2 7 8 . 6 0}$ \\
pH (at moist chamber time) & $\mathbf{7 . 2 7}$ & 6.17 \\
\hline Forest related & & \\
Tree height (m) & $\mathbf{1 6 . 4 6}$ & 7.45 \\
Tree diameter (cm) & $\mathbf{1 5 8 . 8 3}$ & 33.27 \\
Number of trees/200m ${ }^{2}$ & 16 & $\mathbf{2 4}$ \\
Basal area (m $\left.{ }^{2} / \mathrm{ha}\right)$ & $\mathbf{5 4 . 0 8}$ & 10.56 \\
Canopy openness (\%) & 17.67 & $\mathbf{2 1 . 8 3}$ \\
LAI & $\mathbf{1 . 8 7}$ & 1.78 \\
\hline
\end{tabular}

\section{Acknowledgements}

This study was supported by the Slime Mold Project at the University of Arkansas and by project 570-B8-006 from the Vicerrectoría de Investigación at Universidad de Costa Rica. Appreciation is extended to Barbara Stephenson and Shiori Nakajima for support in the field and to the authorities of both the Pea Ridge National Military Park and the Finca Experimental Interdisciplinaria de Modelos Agroecológicos (FEIMA) for granting the research permits.

\section{References}

Baldrian P. 2017 - Microbial activity and the dynamics of ecosystem processes in forest soils. Current Opinion in Microbiology 37, 128-134.

Cavicchioli R, Ripple WJ, Timmis KN, Azam F et al. 2019 - Scientists' warning to humanity: microorganisms and climate change. Nature Review Microbiology 17, 569-586.

Chao A, Chun-Huo C. 2016 - Bridging the variance and diversity decomposition approaches to beta diversity via similarity and differentiation measures. Methods in Ecology and Evolution 7(8), 919-928.

Fukasawa Y, Takahashi K, Ariwaka T, Hattori T, Maekawa N. 2015 - Fungal wood decomposer activities influence community structures of myxomycetes and bryophytes on coarse woody debris. Fungal Ecology 14, 44-52. 
Hammer Ø, Harper DAT, Ryan PD. 2001 - PAST: Paleontological Statistics software package for education and data analysis. Palaeontologia Electronica 4(1), 9.

Harkönen M. 1981 - Myxomycetes developed on litter of common Finnish trees in moist chamber cultures. Nordic Journal of Botany 1, 791-794.

Keller AB, Phillips RP. 2019 - Leaf litter decay rates differ between mycorrhizal groups in temperate, but not tropical, forests. New Phytologist 222, 556-564.

Lado C. 2005-2020 - An online nomenclatural information system of Eumycetozoa. http://www.nomen.eumycetozoa.com. (Accessed 25 July 2020).

Martin GW, Alexopoulos CJ. 1969 - The Myxomycetes. University of Iowa Press, Iowa City.

Martin GW, Alexopoulos CJ, Farr ML. 1983 - The Genera of Myxomycetes. University of Iowa Press, Iowa City.

Martinelli LA, Piccolo MC, Townsend AR, Vitousek PM et al. 1999 - Nitrogen stable isotopic composition of leaves and soil: Tropical versus temperate forests. Biogeochemistry 46, 4565.

Mora-Chacón J, Nakajima S, Rojas PA, Rojas C. 2019 - Effect of forest cover on soil characteristics at the Finca Experimental Interdisciplinaria de Modelos Agroecológicos: a case study. Revista InterSedes 42(20), 208-224.

Nye PH. 1960 - Organic matter and nutrient cycles under moist tropical forest. Plant and Soil 13, 333-346.

Rojas C, Schnittler M, Biffi D, Stephenson SL. 2008 - Microhabitat and niche separation in species of Ceratiomyxa. Mycologia 100, 843-850.

Rollins AW, Stephenson SL. 2012 - Myxogastrid distribution within the leaf litter microhabitat. Mycosphere, 3(5), 543-549.

Stephenson SL. 1989 - Distribution and ecology of myxomycetes in temperate forests. II. Patterns of occurrence on bark surface of living trees, leaf litter, and dung. Mycologia 81, 608-621.

Stephenson SL, Landolt JC, Moore DL. 1999 - Protostelids, dictyostelids, and myxomycetes in the litter microhabitat of the Experimental Forest, Puerto Rico. Mycological Research 103, 209214.

Stephenson SL, Rojas C. 2020 - Mosses as spore traps for myxomycetes. Sydowia 72, 215-219.

Stephenson SL, Stauffacher RW, Rojas C. 2020 - Myxomycetes collected in the eastern United States and patterns of relative biodiversity, Mycology Doi: 10.1080/21501203.2019.1710302

Stephenson SL, Stempen H. 1994 - Myxomycetes, a Handbook of Slime Molds. Timber Press, Portland, Oregon.

Stephenson SL, Wrigley de Basanta D, Lado C, Estrada-Torres A, Darrah R. 2019 - Myxomycete biodiversity revealed in the Namib desert. South African Journal of Botany 124, 402-413.

Vitousek P. 1984 - Litterfall, nutrient cycling, and nutrient limitation in tropical forests. Ecology 65(1), 285-298. 